\title{
REFLEXÕES SOBRE A PRIVACIDADE NA SOCIEDADE DA INFORMAÇÃO
}

\section{REFLEXIONES SOBRE LA PRIVACIDAD EN LA SOCIEDAD DE LA INFORMACIÓN}

\author{
Tânia da Costa Calheiros - calheirostc@gmail.com \\ Mestranda no Programa de Pós-Graduação Ciência da \\ Informação da Universidade Estadual de Londrina (UEL). \\ Thalles Alexandre Takada - thalles@arraesconsultoria.com.br \\ Mestre em Direito Negocial pela Universidade Estadual de \\ Londrina (UEL).
}

\begin{abstract}
RESUMO
Introdução: $O$ artigo aborda as mudanças de paradigmas da privacidade na sociedade da informação.

Objetivo: O objetivo principal deste artigo é contextualizar as mudanças legislativas ocorridas nos últimos 10 anos relacionadas ao direito à privacidade no mundo atual.

Metodologia: A metodologia utilizada foi a pesquisa bibliográfica referente aos últimos10 anos (2005-2015) de atualizações da Constituição Federal, do Código Civil e demais legislações especiais.

Resultados: A revisão e discussão da literatura sobre Internet, ambiente virtual, violação de direitos e sanções, demonstraram que o direito à privacidade sofreu alteração legislativa.

Conclusões: Constatou-se que as legislações advindas do contexto da sociedade digital são tentativas de respostas eficazes às necessidades da sociedade civil brasileira e do Poder Judiciário Brasileiro.
\end{abstract}

Palavras-chave: Sociedade da informação. Privacidade. Internet. Revolução social.

\section{INTRODUÇÃO}

A sociedade da informação, na atualidade, é mais complexa do que em um passado muito recente. O direito evoluiu de uma forma que 
passou a ocupar um espaço além do físico. A sociedade, a economia e a cultura sempre em formação são agora direcionadas pela tecnologia da informação. A internet e as novas tecnologias possibilitaram um acesso ao conhecimento de forma imediata.

A tecnologia adaptou-se ao cotidiano do indivíduo, modificou suas relações e o realocou no espaço social que se situava. A sociedade informacional reordenou a maneira de viver, interligou os continentes e criou a cultura digital. Essa cultura incorporou à vida do indivíduo de forma rápida, porém imprevisível.

O dinamismo da sociedade digital ligou mais do que as culturas de diversos países, mas também demonstrou a fragilidade que os novos dispositivos tecnológicos podemtrazer à vida das pessoas. Essa fragilidade pode trazer prejuízos à pessoa humana, atingindo sua honra, imagem, dignidade e, para este trabalho, especificamente, a intimidade.

Dessa forma, abordagem do presente trabalho busca demonstrar a grande transformação na própria concepção de privacidade. Busca-se também, de forma analítica, averiguar a construção legislativa e a mudança do operador do direito, no que concerne à subsunção do fato à norma, ao se deparar com os choques paradigmáticos ocorridos no bojo da sociedade da informação.

Para não abranger um campo analítico demasiadamente extenso, delimitou o período legislativo de 10 anos (2005-2015), analisando a mudança de perspectiva das normas a alguns casos concretos, tendo em vista a alta mutabilidade dos sistemas tecnológicos que criam a sociedade digital.

Pela escassez doutrinária de temas que dizem respeito ao direito e às tecnologias, a metodologia utilizada foi restrita à pesquisa bibliográfica, desde livros de renomados autores da área social, econômica e do direito, bem como autores da área da tecnologia, que gradativamente vêm criando uma doutrina específica da área digital. 


\section{SOCIEDADE DA INFORMAÇÃO}

Revoluções culturais, tecnológicas, científicas e informacionais emergem paralelas à ocorrência de conflitos, guerras, num contexto de globalização e imperialismo moderno transformando a sociedade, as ciências, a política e o ser humano. A tecnologia evolui em um ritmo frenético, as pessoas estão conectadas de uma forma em que o tempo e o espaço não são mais relevantes. "Nossas sociedades estão cada vez mais estruturadas em uma oposição bipolar entre a Rede e o Ser." (CASTELLS, 2005, p. 41).

Esses eventos de um breve século são fundamentais para as mudanças paradigmáticas da sociedade, as quais são tão drásticas quanto os processos de transformação tecnológica e econômica (CASTELLS, 2005). O fruto de uma criação e destruição capitalista (SCHUMPETER, 1961), posiciona a tecnologia como incremento necessário para o desenvolvimento econômico-social. Uma forma diferente de abordar o direito, com a presença de novos elementos, posiciona os juristas e cria uma inesgotável fonte de intercâmbio do conhecimento. As tecnologias que são estrategicamente decisivas em cada período, "[...] embora não determine a evolução histórica e a transformação social, [...] incorpora a capacidade de transformação das sociedades." (CASTELLS, 2005, p. 44).

A evolução do direito e das tecnologias é um processo abrangente, sendo o reflexo da transformação social, no qual deve ser analisado o sistema capitalista dominante, dependente da heterogeneidade cultural de diversos países, das instituições nele inseridas e do processo informacional. Essa nova estrutura social manifesta-se em diferentes aspectos, conforme a adversidade de cultura e instituições em todo o planeta, relacionada ao surgimento de um novo modo de desenvolvimento, o informacionismo (CASTELLS, 2005).

Esse informacionismo das redes globais, que integra os indivíduos demonstra que a tecnologia da informação deu base às transformações ocorridas ao longo do século. Logo, entende-se como 
tecnologia da informação, todas as formas de transmissão, seja mensagens de voz, textos ou imagens, compreendendo desde equipamentos mais rudimentares, como o telégrafo, aos mais modernos computadores existentes.

Esse processamento tecnológico criou uma estrutura que deu sustentáculo à sociedade e demais sistemas derivados desta, como o econômico, a política, a religião, o direito, entre outros. Criou-se assim um espaço comum a todos, integrando diversos sistemas em um espaço além do físico, e readaptando toda uma cultura aplicada ao conhecimento científico. A conjuntura atual demonstra claramente que o ser humano não mais conseguiria viver sem a tecnologia, sendo que hoje os indivíduos mantêm-se conectados diariamente nos mais diferentes dispositivos.

Se fôssemos capazes de entender as mudanças ao nosso redor, então não iria realmente haver mudanças, mas simplesmente o desenvolvimento da situação presente. Tudo o que podemos fazer, portanto, é mapear as mudanças que vemos na esperança de manter a nossa compreensão sobre a nossa situação em rápida mudança. Isto é o que eu chamo ofertas de Cultura Digital (GERE, 2008, p. 12, tradução nossa). ${ }^{1}$

A cultura digital citada por Gere (2008) remete a um aspecto comportamental, que denota todo um complexo que inclui conhecimento, valores, educação, arte, moral, lei e outros costumes adquiridos pelo indivíduo como membro de uma sociedade, que se torna cada vez mais digital. Ou seja, esses novos fatores são alimentados por uma necessidade humana, a qual integra a tecnologia ao ambiente em que se desenvolve.

Engloba um vasto campo em que a palavra digital pode ser, apesar de sua origem restrita, sinônimo de elementos com a presença

\footnotetext{
1 Texto original: "If we were capable of understanding the changesaround us, then they would not truly be changes, butmerely developmentsof the present situation. All we can do therefore is to mapthe changes we see in the hope of maintaining our grasp on ourrapidly changing situation. This is what I hope Digital Culture offers." (GERE, 2008, p.12).
} 
de tecnologias, estendendo a diversas espécies de dispositivos. Contudo a tecnologia toma aspectos de grande abrangência, implicando em relações de incorporação, como também uma posição de hermenêutica, como ações de interpretação do mundo. O termo digital pode representar ou guiar até o modo de vida de um grupo ou grupos de pessoas em um determinado período da história (GERE, 2008).

Desta forma, os problemas sociais mudaram conforme a sociedade. A vida passou a ser regida por sistemas digitais. A sociedade que vivia sob o medo de guerras e terrorismo, passou a ser influenciada também pelo medo virtual. Casos como pirataria virtual, sequestros de dados, calúnia e difamação em redes, entre diversas outras vicissitudes surgidas nesse sistema. A natureza dos problemas é reconfigurada em outra perspectiva, ou seja, não surgiram novos fatores ou novos crimes, mas esses passaram a ocorrer em um novo espaço.

A onda de revoluções nos países árabes foi uma demonstração de que a sociedade digital agregou ao mundo. Inimaginável seria pensar que em uma cidade de 40 mil habitantes na empobrecida região central da Tunísia, após um vídeo de autoimolação por fogo de um comerciante, em forma de protesto contra a cobrança de policiais corruptos, poderia ser o começo de uma revolução que se estendeu para diversos países (CASTELLS, 2013).

Não mais haveria como tratar o Direito sem entender as transformações ocorridas na sociedade digital. A necessidade de positivar normas e adequar ao sistema operante é ínsita ao instrumentalismo interventista do Direito. Logo, faz-se necessário uma análise por menores dos institutos jurídicos, no que se refere à sua principiologia, bem como às normas jurídicas que constituem 0 ordenamento jurídico ao qual a sociedade digital se submete.

\section{PRINCÍPIOS RELACIONADOS À PRIVACIDADE}

Na sociedade da informação, há alguns pilares de sustentação dos direitos e deveres das pessoas chamados de "princípios". Significa 
início, fundamento ou essência de algum fenômeno. Também pode ser definido como a causa primária, o momento, o local ou trecho em que algo, uma ação ou um conhecimento tem origem. Sendo que o princípio de algo seja como origem ou proposição fundamental. Entretanto, tendo maior relevância para o trabalho, limita-se especificadamente àqueles relacionados à privacidade informacional.

Levando em consideração a privacidade como um direito esculpido explicitamente no texto constitucional, o estudo dos princípios faz-se necessário para delimitar ou expandir o escopo necessário a esse direito constitucionalmente garantido. Os anseios da sociedade digital requerem também a adaptação das normas no sentido amplo, considerando a principiologia do direito hierarquicamente superior ao próprio direito positivo. Ressalta-se que nem todos os princípios são expressos em normas, sendo uma criação do próprio direito natural (BOBBIO, 1995).

Não existe um rol taxativo de princípios que implique diretamente à privacidade da pessoa humana, mas um rol exemplificativo que se ajustam ao tratamento dado ao direito de privacidade. Nesse trabalho tratou por bem analisar os seguintes princípios: princípio da lealdade ou da boa-fé, da publicidade, da transparência, da proporcionalidade, da caducidade, da veracidade, da segurança no tratamento, da confidencialidade, da reciprocidade das vantagens, do não-tratamento de dados sensíveis e da responsabilidade objetiva. Dessa forma, uma análise pormenorizada, porém objetiva, deve ser feita a respeito de cada princípio.

O princípio da lealdade ou da boa-fé dispõe que o sujeito que coletou os dados agiu com boa vontade e ética e que os dados devem ser recolhidos com o consentimento do seu titular, sendo vedada a coleta por meio de terceiros. Este princípio é consagrado pelo STJ em todas as áreas do Direito.

O princípio da publicidade é o instituto da transparência e vedação à promoção pessoal. Trata da obrigatoriedade de os responsáveis por banco de dados informarem o público sobre sua 
existência e finalidade. Como desdobramento deste princípio basilar, tem-se o princípio da transparência, o qualse refereao dever de dar ao titular dos dados à satisfação do tratamento de suas informações cedidas.

O princípio da proporcionalidade aborda quanto à adequação dos dados colhidos, pois devem ser pertinentes e não excessivos à finalidade da ação do coletor. Ele tem o objetivo de coibir excessos desarrazoados, por meio da aferição da compatibilidade entre os meios e os fins da atuação, para evitar restrições desnecessárias ou abusivas.

O princípio da caducidade refere-se à guarda das informações por tempo adequado à identificação das pessoas envolvidas apenas durante o período necessário para a conclusão da finalidade da ação. Caducidade é o estado a que chega todo ato jurídico tornando-se ineficaz em consequência de evento surgido posteriormente.

O princípio da veracidade dispõe quanto ao dever de tomar todas as medidas cabíveis e razoáveis para assegurar que os dados inexatos e incompletos sejam apagados ou retificados. Veracidade significa a comprovação daquilo que é verdadeiro, sendo contrário à mentira ou falsidade.

Dessa vez, o princípio da segurança no tratamento assegura que o responsável pelo banco de dados nos quais são armazenados dados pessoais deve adotar medidas técnicas e administrativas que garantam a segurança dessas informações.

O princípio da confidencialidade impõe o dever de sigilo no que se refere ao tratamento dos dados pessoais. Confidencialidade foi definida pela Organização Internacional de Normalização (ISO) como garantir que a informação seja acessível apenas àqueles autorizados a ter acesso e é uma pedra angular da segurança da informação.

Ainda nesse sentido, o princípio da reciprocidade das vantagens determina que os mesmos meios adotados para a coleta de dados pessoais sejam utilizados também para o exercício dos direitos conferidos aos seus titulares. O princípio do não-tratamento de dados sensíveis prevê a proibição do tratamento de dados pessoais que 
revelem a origem racial, étnica, as opiniões políticas, as convicções religiosas ou filosóficas, a filiação sindical, bem como o tratamento de dados relativos à saúde ou à vida sexual do titular.

O princípio da responsabilidade objetiva atesta que os indivíduos que responsáveis pelo banco de dados sejam punidos pelos danos decorrentes do descumprimento ou desrespeito de todos os princípios arrolados acima, independentemente de dolo ou culpa. Em Direito, responsabilidade objetiva é a responsabilidade advinda da prática de um ilícito ou de uma violação ao direito de outrem que, para ser provada e questionada em juízo, independe da aferição de culpa, ou de gradação de envolvimento, do agente causador do dano.

Diante da revolução da informática e das telecomunicações, o direito à privacidade ganha destaque na sociedade digital por ser a sociedade das mídias e redes sociais, em que a vida particular e demais mensagens informacionais dos indivíduos são expostas com muita facilidade e em ampla magnitude.

Nesse contexto, este direito torna-se muito mais arraigado ao princípio fundamental da dignidade da pessoa humana, o qual está situado no artigo $1^{\circ}$, inciso III da Constituição Federativa do Brasil. A pessoa humana passa a ser o centro das atenções do mercado econômico mundial e todos os mecanismos de propaganda incutem a necessidade de valorização pessoal.

\section{A PRIVACIDADE NA SOCIEDADE DA INFORMAÇÃO}

O reflexo social que a inserção de novas tecnologias causou repercutiu além dos meios físicos e virtuais. Esse novo paradigma aprofundou a cognição humana, alterando a maneira de interações entre indivíduos. Hodiernamente. Dessa forma, a proximidade da vida do outro rompe a antiga noção de privacidade.

O Grande Irmão previsto por George Orwell (1949) não se concretizou apenas como um Estado controlador, mas na própria essência individualista do ser humano, no prazer em vigiar a vida alheia, 
no cultismo ao voyeur. As plataformas digitais criaram um campo propício para o modo exibicionista de viver, levando a público e, por vezes, sem distinção da privacidade individual.

A função instrumental do Direito, de solver os anseios sociais, reordena o sistema jurídico a adequar-se aos novos parâmetros digitais. A positivação da norma é demonstrada em diversos dispositivos que consubstanciam o novo viver dos indivíduos da sociedade digital. Nesse sentido, os já existentes dispositivos normativos e novos dispositivos são criados para atender as vicissitudes dessa sociedade, sem desprezar a principiologia inerente à Ciência do Direito.

Hoje, a diversidade de "pragas" virtuais se espalha pela rede, como os malwares, que são softwares maliciosos, os quais classificam como bots, controlam computadores remotamente; os spywares, que monitoram as atividades dos usuários; e os backdoors, que criam uma fragilidade na máquina do usuário para que possíveis invasões ocorram (CASSANTI, 2014). Alguns desses elementos ainda estão alheios às normas positivadas. O direito ainda não conseguiu alcançar, ou melhor dizendo, definir a respeito de questões dos novos elementos "nocivos" surgidos na sociedade digital.

Nessa senda, a privacidade apresenta aspectos diferenciados, tendo em vista as inovaçõestrazidas pela sociedade da informação. Questões como invasões a dispositivos particulares, imagens fotográficas publicadas em sites de relacionamentos ou novos termos como selfie, cyberbulling, phishing, entre outros.

A revolução causada pela sociedade digital também gerou uma revolução no sistema jurídico, seja na forma de interpretar os antigos dispositivos, seja na criação de novas normas jurídicas. Além do já aludido artigo $5^{\circ}$, inciso $\mathrm{X}$ da Constituição Federal, que descreve como direitos fundamentais a intimidade, a vida privada, a honra e a imagem das pessoas, bem como os direitos da personalidade prescritos no Código Civil de 2002, necessitou o legislador criar lei especial tratando diretamente das questões que envolvem a internet, denominando a Lei $\mathrm{n}^{\circ}$ 12.965, de 23 de abril de 2014, como o Marco Civil da Internet. 
Evidente que a privacidade como garantia ou direito de qualquer indivíduo não se restringe a enunciados normativos, tendo em vista a complexidade de relações surgidas no ambiente virtual. Nesse contexto, alguns casos peculiares merecem ser citados.

Quando ocorre invasão à privacidade em que o fato típico constitui crime, a implicação jurídica é clara, no sentido da responsabilidade criminal e cível do transgressor. Caso notório foi de uma famosa atriz que teve seu computador invadido e finalmente foi aprovada a Lei 12.737, de 30 de novembro de 2012 (BRASIL, 2012). Essa lei, também conhecida popularmente como Lei dos Delitos Informáticos, dispõe sobre a tipificação criminal relacionada à invasão de privacidade quanto à proteção de dados e informações pessoais e corporativas localizadas no ambiente virtual ou físico.

O tipo penal, que é o próprio enunciado da norma, representa que o desenvolvimento científico-tecnológico determina uma mudança social que o direito deve seguir. O risco advindo dos novos dispositivos tecnológicos importa na revolução legislativa. "A ciência se converte em causa (entre outras causas concorrentes), expediente definido e fonte de solução em relação aos riscos e, precisamente desse modo, conquista novos mercados da cienticização." (BECK, 2011, p. 235).

Nesse sentido vale citar a lição de Irineu Francisco Barreto Junior (2013, p. 128):

No que concerne à dimensão da mudança social, inequívoco afirmar que a Lei dos Delitos Informáticos, ao alterar o Código Penal, almeja prevenir a ação delituosa, porém não possui alcance de promover mudança na estrutura social. Certamente não foi essa a intenção do legislador, destarte é importante circunscrever a atualização em análise, no contexto das adaptações normativas advindas dos conflitos surgidos com a sociedade da informação. Quanto ao quesito perenidade como fator de proteção contra mudanças intempestivas, ao que tudo indica os efeitos da lei deverão ser duradouros, uma vez que respondem à legitima demanda social e que demonstra proximidade com a consciência coletiva, na qual a necessidade de proteção para os crimes informáticos é manifesta. 
Contudo, fatos comuns e menos claros surgem sem que um agressor possa ser identificado. Por vezes imagens são furtadas diretamente de websites de relacionamento, perfis de redes sociais falsos são criados para denegrir imagens de outras pessoas ou, até mesmo, dados pessoais são divulgados em websites os quais os verdadeiros proprietários não são encontrados ou a hospedagem do referido website pode ter sido registrado em país adverso a que a vítima reside.

Existem casos frequentes que não são sequer abrangidos pelo direito, no que tange ao aspecto normativo positivo. Grandes sites de pesquisas têm o poder de monitorar os acessos de usuários e, consequentemente, detêm um grande banco de dados de informações. Conseguem assim utilizar essas informações para manipular ou incentivar o consumo de vários usuários. A própria plataforma de navegação é "invadida" por propagandas, links patrocinados, mensagens subliminares, entre diversas outras formas de propagandas. De difícil precisão é definir um limiar entre o caso concreto e a invasão de privacidade, entre a propaganda lícita e o abuso de direito, ouum simples informativo no site e a própria invasão de privacidade do usuário. Bastaria ao poder judiciário em adequar esses novos fatos às normas já existentes, suprimindo lacunas legislativas e dando maior efetividade às demandas sociais.

Apesar de a Internet aumentar os riscos de invasão à privacidade, violação à honra ou imagem, os conflitos surgidos nesse espaço virtual tendem a deixar rastros, por ser através sistema de dados os quais são armazenados nos mais diversos servidores. Se por um lado os avanços tecnológicos aumentam os riscos da sociedade digital, por outro lado esses avanços garantem uma maior eficácia probatória, apesar de a principal função do direito ser prevenir, e não punir eventuais delitos. Contudo, têm-se a tendência de registro, do arquivamento de banco de dados, sendo um poderoso instrumento de controle. 
Dessa forma, as normas jurídicas, mais do que resguardar a intimidade da pessoa, devem resguardar sua dignidade, não obstante a forma de ofensa do bem jurídico tratado. Quando há duvidas a respeito do ofensor ou quanto à atribuição da responsabilidade, o Direito ao Esquecimento ${ }^{2}$ deve imperar.

Portanto, percebe-se que as questões fáticas podem ter mudado a forma, mas a substância mantém-se. Não obstante o fato jurídico ter ocorrido no meio virtual ou físico, suas implicações permanecem inalteradas. O direito necessitou remodelar 0 entendimento, a subsunção do fato à norma, mas não o bem jurídico a ser resguardado.

A sociedade digital trouxe ao cotidiano das pessoas inúmeras inovações benéficas, readequou as necessidades destas e possibilitou que um novo espaço surgisse. Entretanto, junto às essas inovações benéficas, os malefícios desse ambiente também surgiram. As tecnologias são uma invenção do ser humano para atender o ser humano. No ponto que essas inovações começarem a tornar o ser humano seus escravos, o direito deve imperar com sua postura coercitiva e tutelar a favor do bem jurídico magno, que é a dignidade da pessoa humana.

\section{CONCLUSÃO}

A sociedade da informação reordenou a maneira de viver, interligou os continentes e criou a cultura digital. Diante da revolução da informática e das telecomunicações, o direito à privacidade ganha destaque na sociedade digital por ser a capital das mídias e redes sociais, em que a vida particular e demais mensagens informacionais dos indivíduos são expostas com muita facilidade e em ampla magnitude.

\footnotetext{
2 Novo entendimento aplicado às questões surgidas na internet. Iniciou-se no tribunal europeu de um caso de um cidadão espanhol em que o tribunal ordenou a empresa Google retirar seus dados do site de pesquisa.
} 
Essa sociedade é um novo mundo sem fronteiras geográficas, mas esse universo precisa de ordenamento para não propiciar a violação de direitos. Logo, a Constituição da República Federativa Brasileira elenca um rol exemplificativo que se ajustam ao tratamento dado ao direito de privacidade. Esse trabalho tratou por bem analisar os seguintes princípios: princípio da lealdade ou da boa-fé, da publicidade, da transparência, da proporcionalidade, da caducidade, da veracidade, da segurança no tratamento, da confidencialidade, da reciprocidade das vantagens, do não-tratamento de dados sensíveis e da responsabilidade objetiva.

A revolução causada pela sociedade digital também gerou uma revolução no sistema jurídico, seja na forma de interpretar os antigos dispositivos, seja na criação de novas normas jurídicas. Além do já aludido artigo $5^{\circ}$, inciso $X$ da Constituição Federal, que descreve como direitos fundamentais a intimidade, a vida privada, a honra e a imagem das pessoas, bem como os direitos da personalidade prescritos no Código Civil de 2002, necessitou o legislador criar lei especial tratando diretamente das questões que envolvem a internet, denominando a Lei $\mathrm{n}^{\circ}$ 12.965, de 23 de abril de 2014, como o Marco Civil da Internet.

Além disso, surge nesse contexto, a Lei 12.737, de 30 de novembro de 2012, conhecida popularmente de Lei dos Delitos Informáticos, a qual dispõe sobre a tipificação criminal relacionada à invasão de privacidade quanto à proteção de dados e informações pessoais e corporativas localizadas no ambiente virtual ou físico.

A proteção da dignidade da pessoa humana é conquista contínua, que pressupõe vigília constante por parte da sociedade. É vital monitorar o ambiente virtual e dar atenção às proposições daqueles que estão comprometidos com essa causa. As tecnologias surgirão e se transformarão a um passo muito mais rápido do que a legislação, cabe ao operador do direito a sensibilidade de adequar esta às demandas sociais. A revolução legislativa é uma consequência de um complexo cultural de uma sociedade cada vez mais moldada pelas novas tecnologias, contudo, o direito não pode ser omisso enquanto 
"delinquentes" virtuais utilizam o ciberespaço para cometer delitos, diante de uma omissão legiferante para um caso concreto.

Deve-se buscar através do Direito Digital estabelecer critérios jurídicos e objetivos capazes de conduzir cada pessoa rumo à privacidade bem vivida na sociedade digital. Logo, o Direito Digital não deve ser somente utilizado para fins profissionais, mas para bem-estar da população e para a formação dos cidadãos desta nova era.

\section{REFERÊNCIAS}

BARRETO JUNIOR, Irineu F. Aspectos sociológicos da Lei dos delitos informáticos na sociedade da informação. In: PAESANI, Liliana M.

Direito na sociedade da informação III: a evolução do direito digital. São Paulo: Atlas, 2013. p. 113-130.

BOBBIO, Norberto. O positivismo jurídico: lições de filosofia do direito. São Paulo: Ícone, 1995.

BRASIL. Lei $\mathbf{n}^{\circ}$ 12.737, de 30 de novembro de 2012. Dispõe sobre a tipificação criminal de delitos informáticos; altera o Decreto-Lei no 2.848, de 7 de dezembro de 1940 - Código Penal; e dá outras providências. Disponível em: <http://www.planalto.gov.br/ccivil_03/_ato20112014/2012/lei/l12737.htm>. Acesso em: 26 jun. 2015.

BECK, Ulrich. Sociedade de risco: ruma a outra modernidade. Tradução de Sebastião Nascimento. São Paulo: Editora 34, 2011.

CASSANTI, Moisés O. Crimes virtuais, vítimas reais. Rio de Janeiro: Brasport, 2014.

CASTELLS, Manuel. A sociedade em rede. 8.ed. Tradução de Roneide Vanancio Majer. São Paulo: Paz e Terra, 2005. (A era da informação: economia, sociedade e cultura; 1 ).

Redes de indignação e esperança: movimentos sociais na era da internet. Tradução: Carlos Alberto Medeiros. Rio de Janeiro: Zahar, 2013.

GERE, Charlie. Digital culture. London: Reaktion Books, 2008.

ORWELL, George. 1984. Tradução de Wilson Velloso. São Paulo: Companhia Editora Nacional, 1949.

SCHUMPETER, Joseph A. Capitalismo, socialismo e democracia. Traduzido por Ruy Jungmann. Rio de Janeiro: Fundo de Cultura, 1961. 
Tânia da Costa Calheiros; Thalles Alexandre Takada

Reflexões sobre a privacidade na sociedade da informação

\section{Title}

Reflections about privacy in the information society

Abstract

Introduction: The article discusses the revolution of the right to privacy in the information society.

Objective: The main objective of this article is to contextualize the legislative changes in the last 10 years related to the right to privacy today.

Methodology: The methodology used in this bibliographic research for the last 10 years (2005-2015) updates of the Federal Constitution, the Civil Code and other special laws.

Results: The review and discussion of the literature on the Internet, virtual environment, violation of rights and penalties, showed that the right to privacy suffered legislative change.

Conclusions: It was found that the laws that come from the digital society context are attempts to effectively address the needs of the Brazilian civil society and the Brazilian Judiciary.

Keywords: Information society. Privacy. Internet. Social revolution.

\section{Título}

Reflexiones sobre la privacidad en la sociedad de la información

\section{Resumen}

Introducción: El artículo aborda la revolución del derecho a la privacidad en la sociedad de la información.

Objectivos: El objetivo principal de este artículo es contextualizar los cambios legislativos en los últimos 10 años en relación con el derecho a la privacidad en la actualidad.

Metodología: La metodología utilizada en esta investigación bibliográfica de los últimos 10 años (2005-2015) de actualizaciones de la Constitución Federal, el Código Civil otras leyes especiales.

Resultados: La revisión y discusión de la literatura mediante Internet, el medio ambiente civil virtual, violación de los derechos y las sanciones, mostraron que el derecho a la intimidad sufrió un cambio legislativo.

Conclusiones: Se encontró que las leyes que vienen del contexto de la sociedad digital son los intentos de abordar eficazmente las necesidades de la sociedad civil brasileña y el Poder Judicial brasileño.

Palabras clave: Sociedad de la información. Privacidad. Internet. Revolución social.

Recebido em: 15/03/2015

Aceito em: 10/09/2015 